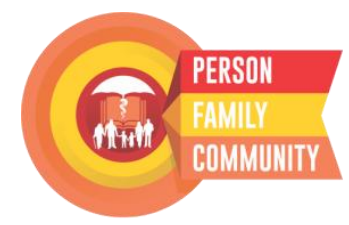

Journal Homepage: https://jurnal.ugm.ac.id/rpcpe

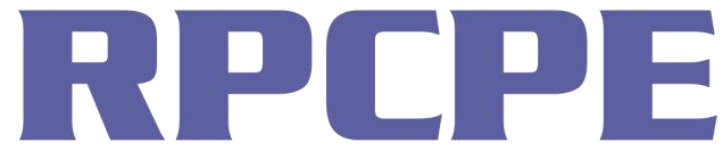

ISSN 2613-943X (print)

Review of Primary Care Practice and Education (Kajian Praktik dan Pendidikan Layanan Primer)

\title{
Type 2 Diabetes Mellitus
}

\author{
Shofi Hesfianto
}

${ }^{1}$ Puskesmas Playen II (Community and Primary Health Care Center); Gunungkidul; Yogyakarta; Indonesia (Training Participant of Primary Care Doctors Preceptors - Ministry of Health Republic of Indonesia 2016)

Corresponding Author:

Shofi Hesfianto: UPT Puskesmas Playen II, Beberan, Playen, Gn. Kidul Kec. Playen, Bleberan, Wonosari, Kabupaten Gunung Kidul, Yogyakarta - 55861, Indonesia

E-mail: shf.hesfianto@gmail.com

To cite this article:

Hesfianto S. Type 2 Diabetes Mellitus. Rev Prim Care Prac and Educ. 2018; 1(1): 44-45.

\section{CASE REPORT}

A female patient aged 44 years came to check the level of blood glucose because of non-healing wounds since an accident 2 weeks ago. The results showed that her blood glucose during the examination was $567 \mathrm{mg} / \mathrm{dl}$. Since 2013, the patient was already diagnosed with Type 2 Diabetes Mellitus (T2DM). At that time the patient experienced vomiting and had to be hospitalized, and apparently her blood glucose level was $538 \mathrm{mg} / \mathrm{dl}$ when she had the same checkup. The patient received treatment according to the national protocol on T2DM. Approximately 2 months after the treatment, the patient discontinued checking the blood glucose and was no longer taking the medicine because she was influenced by information from her relative to not to take continuous medication. The patient was asked by her relative to do only exercise and to discontinue any medicine.

Patient is the second child of 4 siblings. The patient has been married for 22 years and has two children, a 21-year-old female and a 19-year-old male. The patient currently lives at home with her husband and two children. Patient works as an entrepreneur, joining regular in social gatherings at her neighborhood, and has regular spiritual activities at the mosque near her house.

\section{Biological Diagnosis and Psychological Diagnosis}

Biological Diagnosis for T2DM disease is established by examining Fasting Blood Glucose and Blood Glucose 2 hours after meal. In this case, the confirming diagnosis was made after the second examination, which justified the initial diagnosis that was first established in 2013.

Psychosocial diagnosis is established by exploring the patient's reasons for visiting the doctor which was apparently she was concerned that her blood glucose is likely high, although she has been trying to do exercise regularly. Patient's understanding of her illness had not been fully established, and the patient received information from others who advised her on non-medication management of her illness.

\section{PROBLEM}

A patient who was first diagnosed with a chronic disease often does not fully understand the meaning or significance of the chronic disease with which his/ her body suffers, against the risk of future complications if the disease is not well-controlled. On the other hand, in this reported case, the patient's expectation was that her chronic disease, the T2DM, can be cured. Therefore, a shared understanding between health care providers and patient is likely the key to commencing the course of managing any chronic disease in a patient effectively.

\section{DISCUSSION}

According to the current evidences, the diagnosis of T2DM is often found at a younger age than before the many advances in modern medicine. This fact is likely due to a combination of the development of diagnostic criteria, and increases in physician knowledge of diabetes as a disease, and increased public awareness. The diagnosis at younger ages may also reflect the genuine initial population trend in $\mathrm{T}_{2} \mathrm{DM}^{1}$. So it is likely that this patient has suffered from T2DM at a younger age. But perhaps because of inadequate levels of education or access to inadequate health information, the patient did not feel the importance of the symptoms. And even knowing that she was suffering from a chronic disease, in this case T2DM, she did not know the importance of controlling the symptoms and seeking treatment routinely so that her blood glucose was controlled and any organ complications could be avoided and minimized.

Health literacy is defined as the level of a person's ability to obtain, process and understand basic health information and services needed to make the right health decisions. Limited health knowledge, which refers to marginal health literacy, inadequate health knowledge, or both, depending on the definition of the study, have been independently associated with some undesirable outcomes regarding the outcome of health problems ${ }^{2}$. 
Compared to individuals with sufficient levels of health knowledge, those with limited health knowledge have a poorer understanding of their chronic disease, doctor's guidance and health-related websites; less effective disease management skills; higher disease indicator level; and worse health outcome reported. Limited health knowledge is also associated with poor using of certain prevention services, increasing hospitalization, and increasing health care costs. However, all these associations have not been found with perfect consistency ${ }^{2}$.

To increase the level of understanding of a patient concerning chronic illnesses, a good primary care feature recommends a continuity of care approach. Continuity of care is defined as consulting the same health care provider for a certain period of time. It is expected that high provider continuity can have a positive impact on the quality of care because of the growing personal knowledge and personal relationships between patient and service providers. The continuity of primary care is linked to better prevention efforts (including immunization for children and adults), improving patient compliance in the treatment process because of sufficient understanding, improving doctor's ability to identify and address bio-psychosocial problems, and decreasing referral to hospitals and visiting to emergency care. Patients who have access to continuity of care with Family Doctors / Primary Care Doctors, feel more satisfied with their health services, tend to seek follow-up treatment and counselling and communicate better with health personnels ${ }^{3}$.

Another benefit of continuity of care is that it can improve the quality of care for people with chronic conditions, such as T2DM. T2DM as a chronic disease (which cannot be cured but can be managed properly) requires considerable medical management. This medical management tends to be easier when the patient is treated by the same health care provider continuously, because the health care provider will be more likely to know when tests are needed and encourage treatment changes when indicated. A more recent study suggests that higher provider continuity could lead to better glucose control ${ }^{3}$.

Patient management in this case is not yet compatible with the primary care feature of the continuity of care, where a reciprocal relationship between primary care providers and patients is required. If the relationship is achieved optimally then the severity of the disease suffered by the patient does not become worse. Conversely, as occurred in the patient in this case, after experiencing complications from the disease, then the patient continued her medical treatment.

Two-way associations were found between depression and T2DM. Depression is a risk factor for T2DM and T2DM increases the risk of depression. It is not only depression that patients with T2DM commonly feel, it also contributes to adherence to treatment and diet regimens, physical inactivity, poor glycemic control, reduced quality of life, disability, and increasing health expenditure ${ }^{4}$.

To determine the likelihood of patients suffering from depression associated with T2DM, continuous evaluation is needed such as assessment of mental health status. Such a thorough assessment can only be undertaken if the continuity of care occurs.

Preventive Medicine has the potential to improve health in chronic conditions such as T2DM, but many patients in Indonesia are not getting optimal quality health care, so the results are rarely satisfying as happened in this case. Achieving treatment goals for T2DM requires close collaboration between patients, doctors, and other T2DM care team members during a long period of T2DM ${ }^{5}$.

\section{REFERENCES}

1. Koopman RJ, Mainous 3rd AG, Diaz VA, Geesey ME. Changes in age at diagnosis of type 2 diabetes mellitus in the United States, 1988 to 2000. Ann Fam Med [Internet]. 2005;3(1):60-3. Available from: www.annfammed.org

2. Jeppesen KM, Coyle JD, Miser WF. Screening question to predict limited health literacy: a cross-sectional study of patients with diabetes mellitus. Ann Fam Med [Internet]. 2009;7(1):24-31. Available from: www.annfammed.org

3. Gill JM, Mainous 3rd. AG, Diamond JJ, Lenhard MJ. Impact of provider continuity on quality of care for persons with diabetes mellitus. Ann Fam Med [Internet]. 2003;1(3):16270. Available from: www.annfammed.org

4. Bogner HR, Morales KH, de Vries HF, Cappola AR. Integrated management of type 2 diabetes mellitus and depression treatment to improve medication adherence: a randomized controlled trial. Ann Fam Med. 2012;10:15-22.

5. Gulliford MC, Naithani S, Morgan M. Measuring continuity of care in diabetes mellitus: An experience-based measure. Ann Fam Med. 2006;4(6):548-55. 